\title{
Glycemic control and anti-osteopathic effect of propolis in diabetic rats
}

This article was published in the following Dove Press journal:

Diabetes, Metabolic Syndrome and Obesity:Targets and Therapy

2I November 20II

Number of times this article has been viewed

\section{Al-Hariri \\ T Gamal Eldin \\ B Abu-Hozaifa \\ A Elnour}

Department of Physiology, College of Medicine, University of Dammam, Dammam, Saudi Arabia
Correspondence: Mohammed Taha Al-Hariri

College of Medicine, University of Dammam, PO Box 21 I4,

Dammam 3|45I, Saudi Arabia

Tel +966507275028

Fax +9663858077I

Email mohd_alhariri@yahoo.com
Abstract: The aim of the study was to explore the possibility that propolis can control diabetes mellitus and prevent diabetic osteopathy in rats. The study compared 60 streptozotocin (STZ)induced diabetic rats, with ten nondiabetic rats used as a negative control. The experimental design comprised seven groups ( $\mathrm{n}=10$ rats per group): (1) nondiabetic, used as a negative control; (2) nontreated, used as a positive control; (3) treated with insulin alone; (4) treated with a single dose of propolis alone; (5) treated with a double dose of propolis; (6) treated with insulin and a single dose of propolis; and (7) treated with insulin and a double dose of propolis. After 6 weeks of treatment, the rats were sacrificed. Ratios of femur ash to femur weight and of femur weight to body weight (FW/BW) were calculated and calcium $(\mathrm{Ca})$, phosphorus $(\mathrm{P})$, and magnesium $(\mathrm{Mg})$ concentrations in femur ash were estimated and analyzed. Fasting blood glucose (FBG), plasma insulin and glucagon, serum thiobarbituric acid reactive substances (TBARS), plasma parathyroid hormone (PTH), and calcitonin levels were also estimated and analyzed. There was significant reduction in FBG in all diabetic treated rats. Similarly, higher plasma insulin levels were observed in diabetic rats treated with propolis and insulin than in nontreated diabetic rats, although plasma insulin was not comparatively higher in diabetic rats treated with insulin alone. Serum TBARS was significantly lower in the propolis treated rats than the diabetic nontreated rats. No differences in PTH and calcitonin levels were observed among treatment groups. The FW/BW ratio was significantly higher in diabetic treated groups than in control groups. Furthermore, diabetic rats treated with propolis and insulin had significantly higher $\mathrm{Ca}, \mathrm{P}$, and $\mathrm{Mg}$ concentrations in femoral ash than nontreated diabetic rats and diabetic rats treated with insulin alone. In conclusion, propolis has a remarkable effect on glucose homeostasis and bone mineralization.

Keywords: diabetes mellitus, osteopathy, streptozotocin, insulin

\section{Introduction}

Diabetes mellitus (DM) is the most common serious metabolic disorder in humans. It is characterized by hyperglycemia as a result of insulin shortage or insufficient insulin action, or both. ${ }^{1}$ Insulinopenia, which occurs in type 1 diabetes (T1DM), is associated with decreased bone density and a state of low bone turnover. ${ }^{2,3}$

Hyperglycemia is an important factor responsible for the intense oxidative stress in diabetes, and the toxicity induced by glucose autoxidation is likely to be one of the important sources of reactive oxygen species. ${ }^{4}$ Additionally, lipid peroxidation plays an important role in the production of free radicals and oxidative stress in diabetes. ${ }^{5}$ Several intra- and extracellular antioxidant defense mechanisms counteract the destructive effects of free radicals by attenuating or omitting their activities. ${ }^{6}$ However, in DM the oxidative stress exceeds the body's antioxidant defense mechanisms. Although 
oxidative stress and free radicals have been reported to play a significant role in diabetic complications ${ }^{7}$ and treatment with antioxidants has been reported to reduce these complications, ${ }^{8}$ few studies have focused on diabetic osteopathy.

Recent studies have shown that propolis has hypoglycemic, hypolipidemic, and antioxidant activity, ${ }^{9}$ which can be used to prevent or delay the appearance of diabetic complications. Its hypoglycemic activity has been attributed to inhibition of intestinal maltase activity, preventing rise of blood glucose following carbohydrate intake. Propolis has also been reported to enhance the antioxidant defense system ${ }^{10}$ and to protect pancreatic tissue. ${ }^{9}$

In view of recent claims that propolis can cure streptozotocin (STZ)-induced DM, ${ }^{9}$ the authors extend their studies to investigate the effect of propolis on the control of diabetes and the prevention of diabetic osteopathy in STZ-induced diabetic rats.

\section{Material and methods}

Adult male albino rats (obtained from the animal house at the University of Dammam, Dammam, Saudi Arabia) weighing $150-300 \mathrm{~g}$ were housed at a constant temperature $\left(22^{\circ} \mathrm{C}\right)$ under a 12-hour light-dark cycle and were provided with standard rat food and water ad libitum. The University of Dammam ethics committee approved the protocol. The study compared 60 streptozotocin (STZ)-induced diabetic rats, with ten nondiabetic rats used as a negative control. The experimental design comprised seven groups ( $\mathrm{n}=10$ rats per group): (1) nondiabetic, used as a negative control (GI); (2) nontreated, used as a positive control (GII-1); (3) treated with insulin alone (GII-2); (4) treated with a single dose of propolis $(0.3 \mathrm{~g} / \mathrm{kg})$ alone (GII-3); (5) treated with a double dose of propolis $(0.6 \mathrm{~g} / \mathrm{kg})$ (GII-4); (6) treated with insulin and a single dose of propolis $(0.3 \mathrm{~g} / \mathrm{kg})(\mathrm{GII}-5)$; and (7) treated with insulin and a double dose of propolis $(0.6 \mathrm{~g} / \mathrm{kg})(\mathrm{GII}-6)$.

T1DM was induced in the experimental rats ${ }^{11}$ by administering a single-dose intraperitoneal (IP) injection of STZ (60 mg/kg) (Sigma-Aldrich Co, St Louis, MO), dissolved in distilled water. Three days after the STZ injection, urine strips (Medi-Test Combi 10; Macherey-Nagel GmbH \& Co, Düren, Germany) were used to detect glycosuria in rats (a dark-green color indicated blood glucose $\geq 500 \mathrm{mg} / \mathrm{dL}$ ). ${ }^{12}$ These 60 STZ-induced diabetic rats were randomly divided into the six subgroups, GII-1 to GII-6, in the study.

Treatment of all rats included in the study started daily at 7 am and continued for 6 weeks. Both the negative control and positive control groups (GI and GII-1, respectively) received a daily IP injection with normal saline and received $1 \mathrm{~mL}$ of water through a rat feeding needle (Kent Scientific Corporation, Torrington, CT). ${ }^{13}$ Groups GII-2, GII-5, and GII-6 received an IP injection of insulin ( $5 \mathrm{IU} / \mathrm{kg} /$ day) (Humulin; Eli Lilly and Company, Indianapolis, IN). ${ }^{14}$ Groups GII-3 and GII-5 received propolis to ingest (in aqueous solution, $0.3 \mathrm{~g} / \mathrm{kg})^{15}$ and groups GII-4 and GII-6 received a double dose of propolis to ingest (in aqueous solution, $0.6 \mathrm{~g} / \mathrm{kg}){ }^{15}$ through an orogastric metallic needle.

At the end of the 6-week experimental period, the different treatment regimens were stopped, and food was stopped 12 hours before sacrificing the rats. Animals were weighed and then anesthetized with an IP injection of ketamine $(50 \mathrm{mg} / \mathrm{kg})$ (Alfasan International BV, Woerden, the Netherlands). ${ }^{16}$ Blood was collected directly from the abdominal aorta in two tubes by means of a vacutainer. One tube was heparinized for separation of plasma for hormonal studies, while the other tube was kept plain for fasting blood glucose (FBG) and separation of serum to determine the antioxidant activities. Plasma and serum was separated from blood samples by centrifugation at $3000 \mathrm{rpm}$ for 10 minutes at $4^{\circ} \mathrm{C}$, collected, and stored at $-80^{\circ} \mathrm{C}$ until the time of analysis..$^{15}$

\section{Bone sampling}

After drawing blood, the right femurs of all experimental rats were dissected out, cleansed of all soft tissue, washed with distilled water, and allowed to dry at room temperature for 24 hours. Each dried femur was then weighed, put in an oven at $100^{\circ} \mathrm{C}$ for 24 hours, and then put in a furnace at $800^{\circ} \mathrm{C}$ for 12 hours. The ash of each femur was collected separately, weighed, dissolved in $3 \mathrm{~mL}$ of $70 \%$ nitric oxide (SigmaAldrich), and centrifuged; the supernatant was separated for the measurement of calcium $(\mathrm{Ca})$, phosphorus $(\mathrm{P})$, and magnesium $(\mathrm{Mg})$ by the standard colorimetric method. ${ }^{17}$

\section{Plasma insulin, glucagon, calcitonin, and parathyroid hormone}

Plasma enzyme-linked immunosorbent assays (ELISAs) were used to estimate hormone levels. The Insulin ELISA kit (ALPCO Diagnostics, Salem, NH) used for quantitative determination of plasma insulin concentration in rats is a onestep sandwich enzyme immunoassay using two monoclonal antibodies. ${ }^{18}$ Pancreatic glucagon levels were determined by a highly specific ELISA kit (Wako Pure Chemical Industries, Ltd, Richmond, VA), based upon a competitive ELISA using a highly specific antibody to glucagon. ${ }^{19}$ The parathyroid hormone (PTH) kit (ALPCO Diagnostics, Salem, 
$\mathrm{NH}$ ) is a two-site ELISA that quantitatively determines the rat bioactive intact PTH concentrations. ${ }^{18}$ The calcitonin immunoassay kit (Phoenix Pharmaceuticals, Inc, Burlingame, CA) is a competitive enzyme immunoassay that detects calcitonin and its related peptides. ${ }^{20}$

\section{Serum FBG levels and oxidative status}

FBG concentrations were determined by a glucometer (AccuChek Go, Roche Diagnostics GmbH, Indianapolis, IN). ${ }^{6}$ The activity of superoxide dismutase (SOD) (Cayman Chemical, Ann Arbor, MI) was determined through ELISA technique. ${ }^{21}$ Catalase (CAT) (Cayman Chemical) activity was measured using its peroxidative function. ${ }^{22} \mathrm{~A}$ thiobarbituric acid reactive substances (TBARS) assay kit (Cayman Chemical) was used to measure the product of the reaction between malondialdehyde, a product of lipid peroxidation, and TBARS. ${ }^{23}$

\section{Statistical analysis}

All values reported are expressed as mean plus or minus standard error of the mean. Differences among means were analyzed for significance by analysis of variance using SPSS software (v 10; SPSS Inc, Chicago, IL). Groups were then compared by Fisher's least significant difference tests, and $P<0.05$ was considered statistically significant.

\section{Results}

\section{Blood glucose, insulin, and glucagon}

Significant differences in FBG, plasma insulin and glucagon, and insulin-glucagon $(\mathrm{I} / \mathrm{G})$ ratio were noted and are summarized in Table 1. Nontreated diabetic rats (coded NTD) had significantly higher mean FBG than all other groups. The mean blood glucose in all diabetic treated rats (including those treated with propolis only) was not significantly different from the negative control (coded C) group. With regard to plasma insulin, treated groups had significantly lower mean plasma insulin than the negative control group. Further, while the group treated with insulin only (insulin-treated diabetic rats, coded ITD) had plasma insulin comparable with the nontreated diabetic rats, the two groups treated with propolis plus insulin (propolis- and insulin-treated diabetic, coded PITD; doubledose propolis- and insulin-treated diabetic, coded DPITD) had significantly higher plasma insulin than the nontreated diabetic rats. Concerning plasma glucagon, the nontreated diabetic rats had significantly higher plasma glucagon than all other groups. In addition, all groups treated with propolis, with the exception of propolis-treated diabetic (coded PTD) rats, had mean plasma glucagon comparable with that of the negative control group. Treatment with double-dose propolis plus insulin was associated with significantly lower plasma glucagon than the two groups treated with either insulin or propolis alone. The results regarding $\mathrm{I} / \mathrm{G}$ ratio were rather interesting. While the negative control group had a significantly higher I/G ratio than all other groups, the two groups given mixed treatment with insulin plus propolis had a significantly higher $\mathrm{I} / \mathrm{G}$ ratio than the positive control group and those groups treated with either insulin or propolis alone.

\section{Antioxidant parameters}

The mean serum TBARS levels (Figure 1), an indicator of lipid peroxidation, were found to be significantly higher in the nontreated diabetic rats than in the negative control group. Furthermore, the mean serum TBARS levels of all diabetic groups treated with propolis (with or without insulin) were significantly lower than for the nontreated diabetic rats. Serum levels of the two antioxidant enzymes measured (CAT and SOD) were not shown to have significant difference among the studied groups.

Table I Fasting blood glucose (FBG), plasma insulin, plasma glucagon, and insulin-glucagon (I/G) ratio in the control and experimental groups of rats*

\begin{tabular}{lllllll}
\hline Group & Treatment & Code & FBG $(\mathbf{m g} / \mathbf{d L})$ & Insulin $(\mathbf{n g} / \mathbf{m L})$ & Glucagon $(\mathbf{n g} / \mathbf{m L})$ & I/G ratio \\
\hline Nondiabetic & Nontreated & C & $143.9(6.8)$ & $3.0(0.25)$ & $0.417(0.029)$ & $7.182(0.09)$ \\
Diabetic & Nontreated & NTD & $509.3(22.8)^{\mathrm{a}}$ & $0.30(0.04)^{\mathrm{a}}$ & $1.2482(0.16)^{\mathrm{a}}$ & $0.207(0.001)^{\mathrm{a}}$ \\
& Insulin & ITD & $182.0(8)^{\mathrm{b}}$ & $1.10(0.26)^{\mathrm{a}}$ & $0.949(0.078)^{\mathrm{a}, \mathrm{b}}$ & $1.158(0.03)^{\mathrm{a}}$ \\
& Propolis & PTD & $153.7(12.7)^{\mathrm{b}}$ & $0.84(0.3)^{\mathrm{a}}$ & $0.929(0.115)^{\mathrm{a}, \mathrm{b}}$ & $0.842(0.03)^{\mathrm{a}}$ \\
& Double propolis & DPTD & $127.6(17.5)^{\mathrm{b}}$ & $0.85(0.4)^{\mathrm{a}}$ & $0.755(0.142)^{\mathrm{b}}$ & $1.13(0.02)^{\mathrm{a}}$ \\
& Insulin + propolis & PITD & $156.2(12.5)^{\mathrm{b}}$ & $1.50(0.04)^{\mathrm{a}, \mathrm{b}}$ & $0.669(0.889)^{\mathrm{b}}$ & $2.242(0.05)^{\mathrm{a}-\mathrm{e}}$ \\
& Insulin + double propolis & DPITD & $127.1(20.7)^{\mathrm{b}}$ & $1.40(0.06)^{\mathrm{a}, \mathrm{b}}$ & $0.587(0.591)^{\mathrm{b}-\mathrm{d}}$ & $2.382(0.05)^{\mathrm{a}-\mathrm{e}}$ \\
\hline
\end{tabular}

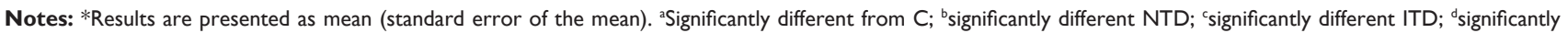
different PTD; esignificantly different from DPTD using one-way analysis of variance at $P<0.05$. There were ten rats in each group.

Abbreviations: C, nondiabetic; DPITD, double-dose propolis- and insulin-treated diabetic; DPTD, double-dose propolis-treated diabetic; ITD, insulin-treated diabetic; NTD, nontreated diabetic; PITD, propolis- and insulin-treated diabetic; PTD, propolis-treated diabetic. 


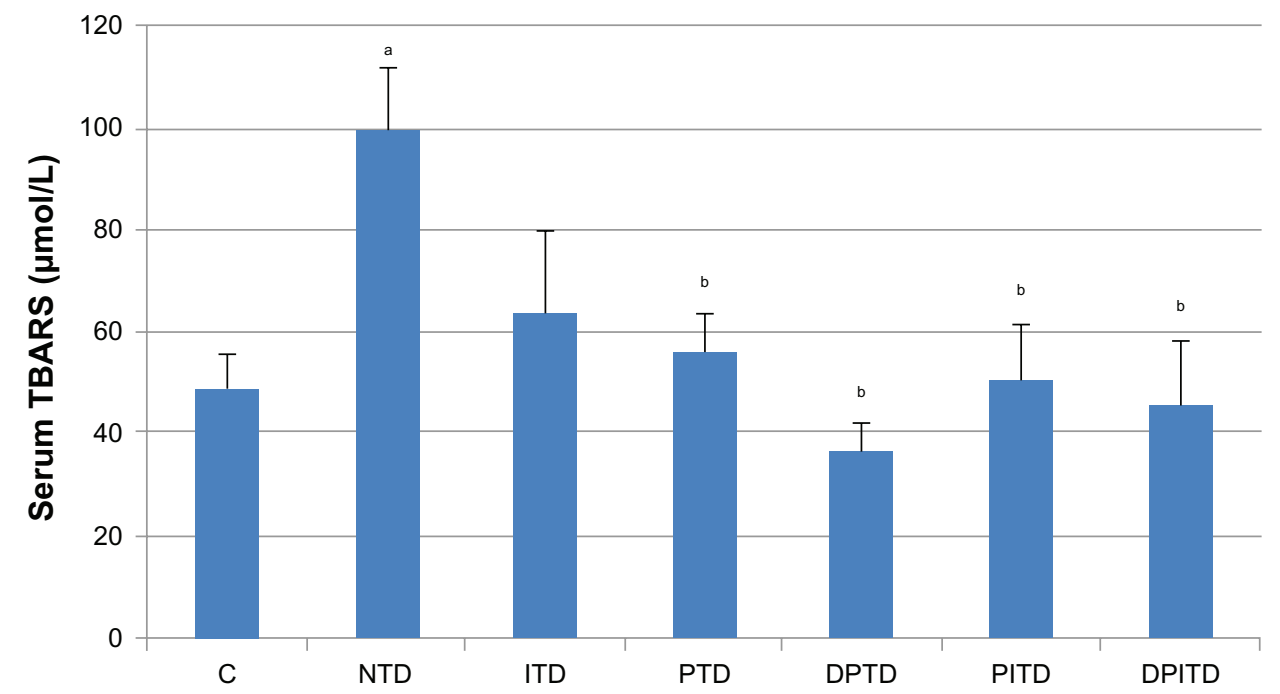

Figure I Mean serum levels of thiobarbituric acid reactive substances (TBARS) in the control and experimental groups of rats.

Notes: aSignificantly different from C; bsignificantly different from NTD using one-way analysis of variance at $P<0.05$. There were ten rats in each group.

Abbreviations: C, nondiabetic; DPITD, double-dose propolis- and insulin-treated diabetic; DPTD, double-dose propolis-treated diabetic; ITD, insulin-treated diabetic; NTD, nontreated diabetic; PITD, propolis- and insulin-treated diabetic; PTD, propolis-treated diabetic.

\section{PTH, calcitonin, and bone mineralization}

The results of plasma PTH, calcitonin, and FW/BW ratio are shown in Table 2. While, the nontreated diabetic rats had significantly higher mean plasma PTH than the negative control group, other groups did not. Moreover, mean serum PTH did not differ significantly between the treated diabetic subgroups. Mean plasma calcitonin was significantly higher in the nontreated diabetic group than in all other groups. In addition, no significant difference in plasma calcitonin among the diabetic treated groups was noted. As regards FW/BW ratio, no significant difference existed between the two control groups, negative and positive. However, the FW/BW ratio was significantly higher for all diabetic treated groups than for the positive control group. In addition, all groups treated with propolis (with or without insulin) had a higher FW/BW ratio than the negative control group. The concentration of ash in femur bones and the concentrations of $\mathrm{Ca}, \mathrm{P}$, and $\mathrm{Mg}$ provided interesting results, as summarized in Table 3. The bones of the negative control group and the two groups treated with insulin plus propolis had significantly higher ash contents than those of the positive control group. Treatment with either insulin or propolis alone did not significantly affect the concentration of ash in femur bones. The concentrations of $\mathrm{Ca}, \mathrm{P}$, and $\mathrm{Mg}$ in femur ash also showed significant differences among groups. The concentrations of these three minerals were significantly lower in the nontreated diabetic group than in all other groups. In addition, all groups treated with propolis (with or without insulin treatment, and with single- or double-dose propolis) had significantly higher ash $\mathrm{Ca}$ and

Table 2 Plasma parathyroid hormone (PTH) and calcitonin levels and ratio of femur weight to body weight (FW/BW) in the control and experimental groups of rats*

\begin{tabular}{llllll}
\hline Group & Treatment & Code & PTH $(\mathbf{p g} / \mathbf{m L})$ & Calcitonin $(\mathbf{p g} / \mathbf{m L})$ & FW/BW ratio \\
\hline Nondiabetic & Nontreated & C & $44(17.1)$ & $1.5(0.16)$ & $0.02(0.001)$ \\
Diabetic & Nontreated & NTD & $65.3(16.5)^{\mathrm{a}}$ & $3.2(0.4)^{\mathrm{a}}$ & $0.014(0.004)$ \\
& Insulin & ITD & $54.2(21.1)$ & $1.6(0.1)^{\mathrm{b}}$ & $0.024(0.003)^{\mathrm{b}}$ \\
& Propolis & PTD & $53 \pm 19.9$ & $1.98(0.1)^{\mathrm{b}}$ & $0.025(0.001)^{\mathrm{a}, \mathrm{b}}$ \\
& Double propolis & DPTD & $50.1(19.5)$ & $1.77(0.3)^{\mathrm{b}}$ & $0.028(0.001)^{\mathrm{a}, \mathrm{b}}$ \\
& Insulin + propolis & PITD & $45.1(20.5)$ & $1.75(0.4)^{\mathrm{b}}$ & $0.028(0.001)^{\mathrm{a}, \mathrm{b}}$ \\
& Insulin + double propolis & DPID & $44.3(20)$ & $1.69(0.3)^{\mathrm{b}}$ & $0.029(0.003)^{\mathrm{a}, \mathrm{b}}$ \\
\hline
\end{tabular}

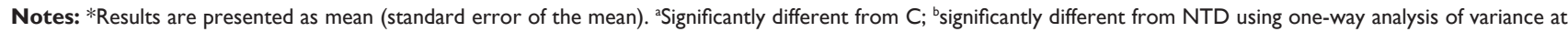
$P<0.05$. There were ten rats in each group.

Abbreviations: C, nondiabetic; DPITD, double-dose propolis- and insulin-treated diabetic; DPTD, double-dose propolis-treated diabetic; ITD, insulin-treated diabetic; NTD, nontreated diabetic; PITD, propolis- and insulin-treated diabetic; PTD, propolis-treated diabetic. 
Table 3 Ratio of femur ash to femur weight (FA/FW) and calcium (Ca), phosphorous ( $\mathrm{P})$, and magnesium (Mg) concentrations in the control and experimental groups of rats*

\begin{tabular}{lllllll}
\hline Group & Treatment & Code & FA/FW ratio & Ca (\%) & P (\%) & Mg (\%) \\
\hline Nondiabetic & Nontreated & C & $5 I .6(3)$ & $40.1(0.95)$ & $19(0.63)$ & $0.8(0.01)$ \\
Diabetic & Nontreated & NTD & $41.9(1.9)^{\mathrm{a}}$ & $21.8(2.55)^{\mathrm{a}}$ & $13.8(0.81)^{\mathrm{a}}$ & $0.6(0.03)^{\mathrm{a}}$ \\
& Insulin & ITD & $45.2(I .3)$ & $34.9(0.88)^{\mathrm{a}, \mathrm{b}}$ & $16.2(0.56)^{\mathrm{a}, \mathrm{b}}$ & $0.68(0.02)^{\mathrm{a}, \mathrm{b}}$ \\
& Propolis & PTD & $43.7(2.1)$ & $39.5(0.5)^{\mathrm{b}, \mathrm{c}}$ & $17.3(0.54)^{\mathrm{a}, \mathrm{b}}$ & $0.76(0.01)^{\mathrm{a}-\mathrm{c}}$ \\
& Double propolis & DPTD & $47.1(2.9)$ & $38.7(0.8)^{\mathrm{b}, \mathrm{c}}$ & $18.4(0.62)^{\mathrm{b}, \mathrm{c}}$ & $0.75(0.01)^{\mathrm{a}-\mathrm{c}}$ \\
& Insulin + propolis & PITD & $48.4(I)^{\mathrm{b}}$ & $37.3(0.89)^{\mathrm{a}-\mathrm{d}}$ & $17.5(0.59)^{\mathrm{a}, \mathrm{b}}$ & $0.74(0.01)^{\mathrm{a}-\mathrm{c}}$ \\
& Insulin + double propolis & DPITD & $50.5(1.8)^{\mathrm{b}, \mathrm{d}}$ & $39.1(1.06)^{\mathrm{b}, \mathrm{c}}$ & $18.2(0.8)^{\mathrm{b}, \mathrm{c}}$ & $0.78(0.01)^{\mathrm{a}-\mathrm{c}, \mathrm{e}}$ \\
\hline
\end{tabular}

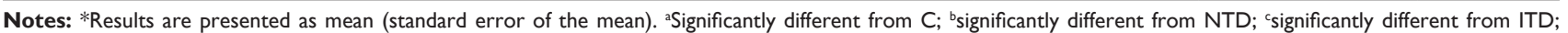
${ }^{d}$ significantly different from PTD; esignificantly different from PITD using one-way analysis of variance at $P<0.05$. There were ten rats in each group.

Abbreviations: C, nondiabetic; DPITD, double-dose propolis- and insulin-treated diabetic; DPTD, double-dose propolis-treated diabetic; ITD, insulin-treated diabetic; NTD, nontreated diabetic; PITD, propolis- and insulin-treated diabetic; PTD, propolis-treated diabetic.

$\mathrm{Mg}$ concentrations than the diabetic group treated with insulin only. Furthermore, double-dose propolis treatment (with or without insulin treatment) was associated with a significantly higher ash $\mathrm{P}$ concentration than insulin-only treatment.

\section{Discussion}

This study on adult male albino rats confirms the earlier reports $^{9}$ that propolis could almost control the hyperglycemia in the STZ-induced diabetic rat model. ${ }^{24}$ The glycemic control achieved by propolis treatment could be due to the stimulation of glucose uptake by peripheral tissues, inhibition of its release in circulation, ${ }^{25}$ or reduced glucose absorption in the gut. ${ }^{10}$

However, the present study shows that propolis treatment in STZ-induced diabetic rats is associated with high plasma insulin and low glucagon levels. These findings suggest that decreased glucose output by the liver and increased glucose uptake by peripheral tissues were the probable mechanisms through which propolis achieved glycemic control.

However, the recovery of insulin secretion in diabetic rats is a partial restoration only, because insulin levels in all diabetic rats treated with propolis were significantly lower than in the negative control group. The source of insulin in propolis-treated diabetic rats could be the $\beta$ cells of the pancreas and therefore two possibilities are suggested: either propolis induces regeneration or it prevents further deterioration of $\beta$ cells. Others have reported similar findings on the ability of propolis to induce regenerative effects on $\beta$ cells. ${ }^{10,11,15}$

As already noted, lipid peroxidation is the most potent oxidative defect that damages $\beta$ cells in T1DM. ${ }^{26}$ All diabetic rats in the study treated with propolis alone or with insulin were observed showing significantly lowered lipid peroxidation levels nearing normal control values, which suggests that propolis prevents deterioration of $\beta$-cell function. This finding confirms the earlier report that propolis causes partial restoration of $\beta$-cell function. ${ }^{11}$ However, the authors could not confirm whether the glycemic control achieved by propolis was also achieved by the inhibition of intestinal glucose absorption, ${ }^{10}$ as the rats were deprived of food for 12 hours before they were sacrificed.

However, propolis administration in the present study could not raise plasma insulin to the levels achieved by exogenous insulin administration, although it significantly lowered blood glucose to reach normal control values. This suggests that propolis administration causes inhibition of glucose release from the liver and/or improvement of peripheral tissue insulin sensitivity.

The study found that a decline in glucagon concentration in propolis-treated rats with elevation of the $\mathrm{I} / \mathrm{G}$ ratio, again suggesting that decline in liver glucose output is an important mechanism in glycemic control by propolis. The study also found that a significant decline of glucagon concentrations in all propolis-treated diabetic rats compared with nontreated diabetic rats is due to insulin-induced inhibition of pancreatic $\alpha$ cells. This is because high insulin levels were found to be associated with significantly low glucagon levels in diabetic rats treated with both propolis and insulin. Additionally, compared with single-dose propolis-treated rats, double-dose propolis-treated rats showed low glucagon levels that were nearing negative control group levels, despite the insulin dose being the same for both groups (propolis-treated diabetic and double-dose propolis-treated diabetic [coded DPTD] rats). However, a direct inhibitory effect of propolis on $\alpha$ cells cannot be excluded and requires further investigation.

Evidence for a direct link between insulin and bone formation in vivo is scant. Recent studies explain the potential 
role of insulin as an anabolic agent in osteoblastogenesis. ${ }^{27}$ Researchers have shown that bone regeneration is impaired by insulin deficiency but that it can be restored by insulin treatment, even with modrate hyperglycemia, indicating a primary role for insulin in bone formation. ${ }^{28}$ Hence, in diabetic states, bone formation rather than bone resorption is affected, leading to bone loss. ${ }^{29}$

The nontreated diabetic group showed serum insulin levels at about $10 \%$ of normal control values, exhibiting pronounced bone loss, reflected in a low ratio of femur ash to femur weight (FA/FW), as well as low bone concentrations of $\mathrm{Ca}, \mathrm{P}$, and $\mathrm{Mg}$ compared with the negative control group. This finding suggests that bone regeneration is impaired by insulin deficiency.

Despite the marked bone loss, FW/BW ratio showed a nonsignificant decline compared with the corresponding ratio from the negative control group. When compared with body weight in the nontreated diabetic group, masking of this bone loss may be secondary to the associated reduction in body weight.

Interestingly, $\mathrm{Ca}$ concentration in ash was reduced by almost $50 \%$ and that of $\mathrm{P}$ was reduced by about $30 \%$ only in nontreated diabetic rats, compared with the ones in the control group. Similar findings have been reported in insulin deficiency ${ }^{30}$ being associated with a decrease in both ash content and ratio of $\mathrm{Ca}$ to $\mathrm{P}$ in tibia ash. In another study in insulin deficiency, ${ }^{31}$ a significant decrease $(>50 \%)$ of bone volume fraction in the tibia and femur of mice was demonstrated. Consistent loss of bone mass was detected by cytophotometry, due to a deficit in mineralized surface area in an untreated insulin-deficient state. ${ }^{32}$

In the present study, diabetic rats treated with propolis (with or without insulin) showed an increased FW/BW ratio compared with nontreated diabetic rats and the negative control group, reflecting an increased bone mass. On the other hand, only diabetic rats treated with propolis plus insulin showed a significant increase in the FA/FW ratio when compared with nontreated diabetic rats. However, the most striking feature was that all groups of diabetic rats treated with propolis (with or without insulin) showed $\mathrm{Ca}$ and $\mathrm{Mg}$ values significantly higher than nontreated diabetic rats and those diabetic rats treated with insulin alone, reflecting improvement of bone mineral content. Specifically, the double-dose propolis-treated groups (with or without insulin) showed $\mathrm{Ca}$ concentration levels in femur ash closer to those of the negative control group; Ca levels in nontreated diabetic rats were about $50 \%$ of the negative control.
The diabetic group also showed a significant rise of serum PTH and calcitonin levels as compared with the negative control group. PTH elevation is another factor for inducing bone loss, through both bone osteolysis and resorption. ${ }^{33}$ This increase of serum PTH levels in diabetic rats could be due to an increase in $\mathrm{Ca}$ excretion accompanying glycosuria and a decreased $\mathrm{Ca}$ absorption secondary to deficiency of vitamin D. ${ }^{34}$ The mechanism behind the double rise in calcitonin concentration in diabetic rats and their return to normal levels by the different treatment regimen may provide a protective effect, ameliorating the bone loss effects of insulin deficiency and PTH elevation. However, this is not clear and needs further investigation.

In the present study, propolis showed remarkable effects on bone minerals, and therefore on bone mass, especially when administered with insulin to STZ-induced diabetic rats. Previous studies have reported propolis to have exerted an inhibitory action on osteoclasts, leading to attenuation of osteoclastogenesis, compared with insulin and its anabolic effects on bone osteoblasts. ${ }^{35}$ Another experimental study has reported that propolis inhibits late stages of osteoclast maturation, including fusion of osteoclast precursors to form giant cells. ${ }^{36}$ At the molecular level, an earlier study has documented that propolis has dual effects on osteoclasts: it inhibits osteoclastogenesis and it induces apoptosis. ${ }^{37}$ It has also been reported that hyperglycemia contributes to diabetic bone complications through a variety of mechanisms including increasing the reactive oxygen species, ${ }^{37,38}$ polyol pathway activity, ${ }^{39}$ and protein kinase $\mathrm{C}$ activity. ${ }^{40}$ In addition, hyperglycemia can induce an osmotic response in cells such as osteoblasts, leading to suppression of their activity. ${ }^{41}$

In this study, the authors observed that propolis administration through its glycemic control may play an important role in prevention of bone loss associated with the hyperglycemic state. In particular, the double propolis dose combined with insulin treatment could almost return bone mineralization to normal control levels. Therefore, the authors propose that when administered together, insulin, with its potent effect on bone formation, and propolis, with its inhibitory effect on bone resorption, can provide a promising therapy to protect against bone loss in T1DM.

\section{Conclusion}

In conclusion, experimental treatment of STZ-induced diabetic rats with propolis and insulin was found to effectively control blood glucose level, improve function of the pancreatic islets, eliminate the oxidative stress, and protect bone from diabetic osteopathy. Clinical application 
of this combined therapy in humans requires further investigation and evaluation of its effectiveness and safety in T1DM patients.

\section{Acknowledgments}

All authors contributed to the design and coordination of the research, analysis of data, and writing of the manuscript. All authors read and approved the final manuscript, and all authors share responsibility for the final contents of this article. The authors wish to express their appreciation to King Abdulaziz City for Science and Technology, Riyadh, Saudi Arabia, for financial support.

\section{Disclosure}

The authors report no conflicts of interest in this work.

\section{References}

1. Zimmet PZ, McCarty DJ, de Courten MP. The global epidemiology of non-insulin-dependent diabetes mellitus and the metabolic syndrome. J Diabetes Complications. 1997;11(2):60-68.

2. López-Ibarra PJ, Pastor MM, Escobar-Jiménez F, et al. Bone mineral density at time of clinical diagnosis of adult-onset type 1 diabetes mellitus. Endocr Pract. 2001;7(5):346-351.

3. Ishida H, Seino Y, Taminato $\mathrm{T}$, et al. Circulating levels and bone contents of bone gamma-carboxyglutamic acid-containing protein are decreased in streptozocin-induced diabetes: possible marker for diabetic osteopenia. Diabetes. 1988;37(6):702-706.

4. Giugliano D, Ceriello A, Paolisso G. Oxidative stress and diabetic vascular complications. Diabetes Care. 1996;19(3):257-267.

5. Halliwell B, Gutteridge JM. Lipid peroxidation, oxygen radicals, cell damage, and antioxidant therapy. Lancet. 1994;1(8391): 1396-1397.

6. Afshari AT, Shirpoor A, Farshid A, et al. The effect of ginger on diabetic nephropathy, plasma antioxidant capacity and lipid peroxidation in rats. Food Chem. 2007;101:148-153.

7. Hamada Y, Fujii H, Kitazawa R, Yodoi J, Kitazawa S, Fukagawa M. Thioredoxin-1 overexpression in transgenic mice attenuates streptozotocin-induced diabetic osteopenia: a novel role of oxidative stress and therapeutic implications. Bone. 2009;44(5):936-941.

8. Yilmaz HR, Uz E, Yucel N, Altuntas I, Ozcelik N. Protective effect of caffeic acid phenethyl ester (CAPE) on lipid peroxidation and antioxidant enzymes in diabetic rat liver. J Biochem Mol Toxicol. 2004;18(4): 234-238

9. El-Sayed el-SM, Abo-Salem OM, Aly HA, Mansour AM. Potential antidiabetic and hypolipidemic effects of propolis extract in streptozotocin-induced diabetic rats. Pak J Pharm Sci. 2009;22(2): $168-174$.

10. Matsui T, Ebuchi S, Fujise T, et al. Strong antihyperglycemic effects of water-soluble fraction of Brazilian propolis and its bioactive constituent, 3,4,5-tri-O-caffeoylquinic acid. Biol Pharm Bull. 2004;27(11): 1797-1803.

11. Noorafshan A, Esmail-Zadeh B, Bahmanpour S, Poost-Pasand A. Early stereological changes in liver of Sprague-Dawley rats after streptozotocin injection. Indian J Gastroenterol. 2005;24(3):104-107.

12. Wang NZ, Li D. Effect of combined propolis-ethanol-extract and Shaoyao-Gancao-tang on blood sugar levels in rabbits with alloxan induced experimental diabetes. Asia Pac J Clin Nutr. 2004;13 Suppl:S66.

13. Baker H, Lindsey J, Weisbroth S. Biology and Disease. The Laboratory Rat II: Research Applications. Orlando, FL: Academic press; 1980:276.
14. Xing Y, Sonner J, Laster MJ, et al. Insulin decreases isoflurane minimum alveolar anesthetic concentration in rats independently of an effect on the spinal cord. Anesth Analg. 2004;98(6):1712-1717.

15. Matsushige K, Basnet P, Hase K, Kodota S, Tanaka K, Namba T. Propolis protects pancreatic beta-cells against the toxicity of streptozotocin (STZ). Phytomedicine. 1996;3(2):203-209.

16. Lei H, Nwaigwe CI, Williams H, Dunn JE. Effects of ketamine and ketamine-xylazine anesthesia on cerebral blood flow in rat observed using arterial spin tagging perfusion imaging. Proc Int Soc Mag Reson Med. 2001;9:1488.

17. Norazlina M, Ima-Nirwana S, Abul Gapor MT, Abdul Kader Khalid B. Tocotrienols are needed for normal bone calcification in growing female rats. Asia Pac Clin Nutr. 2002;11(3):194-199.

18. Findlay JW, Dillard RF. Appropriate calibration curve fitting in ligand binding assays. AAPS J. 2007;9(2):E260-E267.

19. Jaspan JB, Rubenstein AH. Circulating glucagon: plasma profiles and metabolism in health and disease. Diabetes. 1977;26(9):887-904.

20. Porstmann T, Kiessig ST. Enzyme immunoassay techniques: an overview. J Immunol Methods. 1992;150(1-2):5-12.

21. McCord JM, Fridovich I. Superoxide dismutase: an enzymatic function for erythrocuprein (hemocuprein). J Biol Chem. 1969;244(22): 6049-6055.

22. Armstrong D, Browne R. The analysis of the free radicals, lipid peroxides, antioxidant enzymes and compounds related to oxidative stress as applied to the clinical chemistry laboratory. Adv Exp Med Biol. 1994; 366:43-58.

23. Rungby J, Ernst E. Experimentally induced lipid peroxidation after exposure to chromium, mercury and silver: interactions with carbon tetrachloride. Pharmacol Toxicol. 1992;70(3):205-207.

24. Thulesen J, Orskov C, Holst JJ, Poulsen SS. Short-term insulin treatment prevents the diabetogenic action of streptozotocin in rats. Endocrinology. 1997;138(1):62-68.

25. Lee ES, Uhm KO, Lee YM, et al. CAPE (caffeic acid phenethyl ester) stimulates glucose uptake through AMPK (AMP-activated protein kinase) activation in skeletal muscle cells. Biochem Biophys Res Commun. 2007;361(4):854-858.

26. Okutan H, Ozcelik N, Yilmaz RH, Uz E. Effects of caffeic acid phenethyl ester on lipid peroxidation and antioxidant enzymes in diabetic rat heart. Clin Biochem. 2005;38(2):191-196.

27. Akune T, Ogata N, Hoshi K, et al. Insulin receptor substrate-2 maintains predominance of anabolic function over catabolic function of osteoblasts. J Cell Biol. 2002;159(1):147-156.

28. Thrailkill KM, Lumpkin CK Jr, Bunn RC, Kemp SF, Fowlkes JL. Is insulin an anabolic agent in bone? Dissecting the diabetic bone for clues. Am J Physiol Endocrinol Metab. 2005;289(5): E735-E745.

29. Botolin S, Faugere MC, Malluche H, Orth M, Meyer R, McCabe LR. Increased bone adiposity and peroxisomal proliferator-activated receptor-gamma2 expression in type I diabetic mice. Endocrinology. 2005;146(8):3622-3631.

30. Einhorn TA, Boskey AL, Gundberg CM, Vigorita VJ, Devlin VJ, Beyer MM. The mineral and mechanical properties of bone in chronic experimental diabetes. J Orthop Res. 1988;6(3):317-323.

31. Martin LM, McCabe LR. Type I diabetic bone phenotype is location but not gender dependent. Histochem Cell Biol. 2007;128(2):125-133.

32. Bachrach LK. Dual energy X-ray absorptiometry (DEXA) measurements of bone density and body composition: promise and pitfalls. J Pediatr Endocrinol Metab. 2000;13 Suppl 2:983-988.

33. Iida-Klein A, Hahn TJ. Insulin acutely suppresses parathyroid hormone second messenger generation in UMR-106-01 osteoblast-like cells: differential effects on phospholipase $\mathrm{C}$ and adenylate cyclase activation. Endocrinology. 1991;129(2):1016-1024.

34. Fitzpatrick LA. Secondary causes of osteoporosis. Mayo Clin Proc. 2002;77(5):453-468.

35. Ha J, Choi HS, Lee Y, Lee ZH, Kim HH. Caffeic acid phenethyl ester inhibits osteoclastogenesis by suppressing NF kappaB and downregulating NFATc1 and c-Fos. Int Immunopharmacol. 2009;9(6):774-780. 
36. Pileggi R, Antony K, Johnson K, Zuo J, Shannon Holliday L. Propolis inhibits osteoclast maturation. Dent Traumatol. 2009;25(6): 584-588.

37. Ang ES, Pavlos NJ, Chai LY, et al. Caffeic acid phenethyl ester an active component of honeybee propolis attenuates osteoclastogenesis and bone resorption via the suppression of RANKL-induced NF-kappaB and NFAT activity. J Cell Physiol. 2009;221(3):642-649.

38. Hunt JV, Smith CC, Wolff SP. Autoxidative glycosylation and possible involvement of peroxides and free radicals in LDL modification by glucose. Diabetes. 1990;39(11):1420-1424.
39. Inaba M, Nishizawa Y, Shioi A, Morii H. Importance of sustained high glucose condition in the development of diabetic osteopenia: possible involvement of the polyol pathway. Osteoporos Int. 1997;7 Suppl 3: S209-S212.

40. Ceolotto G, Gallo A, Miola M, et al. Protein kinase C activity is acutely regulated by plasma glucose concentration in human monocytes in vivo. Diabetes. 1999;48(6):1316-1322.

41. Thomas DM, Maher F, Rogers SD, Best JD. Expression and regulation by insulin of GLUT 3 in UMR 106-01, a clonal rat osteosarcoma cell line. Biochem Biophys Res Commun. 1996;218(3):789-793.

\section{Publish your work in this journal}

Diabetes, Metabolic Syndrome and Obesity: Targets and Therapy is an international, peer-reviewed open-access journal committed to the rapid publication of the latest laboratory and clinical findings in the fields of diabetes, metabolic syndrome and obesity research. Original research, review, case reports, hypothesis formation, expert opinion and commentaries are all considered for publication. The manuscript management system is completely online and includes a very quick and fair peer-review system, which is all easy to use. Visit http://www.dovepress.com/testimonials.php to read real quotes from published authors.

Submit your manuscript here: http://www.dovepress.com/diabetes-metabolic-syndrome-and-obesity-targets-and-therapy-journal 